Lithium Lens Interlocks

J. Krider

$12 / 18 / 85$ 
J. Krider

$12 / 18 / 85$

\section{Lithium Lens Interlocks}

The lithium lens in the antiproton source target vault is protected by an interlock system, which is located in relay racks $\mathrm{R} 5$ and R6 near the southwest corner of the Target Hall (building APO). The interlock system consists of crates of commercial signal conditioner and alarm modules built by Acromag, Inc and interlock Master Modules built by Fermilab.

Twenty analog signals from the lens/transformer, power supply, and cooling water system are buffered with signal conditioners (amplifiers), which are located in creates R5C and R5E. The signals and conditioner assignments are listed in Table 1. Interconnection details are shown in Figure 1. Thermocouple signals come into the conditioners directly from the vault or water system via 12-pair multiconductor thermocouple extension cables. All other signals pass through a master connection panel on the east end of rack $R 6$. Water flow signals are AC voltages which must be converted by electronics in crate $D 2 B$ to DC voltages before entering their signal conditioners.

Each conditioner drives two parallel outputs. One output goes to a Multiplexed Analog to Digital Converter (MADC 25), which is located in R5D. This voltage output is read by the accelerator control network (ACNET) and can be displayed at any control console on parameter page P46. The other voltage output is connected to an alarm module.

Thirteen analog signals are processed by alarm modules, which are located in crates $R 6 B$ and $R 6 C$. Alarm connection details are shown in Figure 2. Each alarm module contains two DPDT relays, one for an upper limit and one for a lower limit. The relays are latching, so that once an input has passed outside a limit, that limit relay remains in the tripped condition until an operator issues a reset pulse. The reset may be generated locally with a pushbutton on the appropriate interlock master module or remotely from controls parameter page P46 via ACNET. Alarm settings are summarized in engineering units in Table 1, and actual comparitor voltage settings are 1 isted in Figure 2 .

Each alarm crate contains 10 module slots and is wired as shown in Figure 3, except for the water conductivity slot, which is wired to a separate interlock chain output. Normally open contacts are used for interlock chains, while normally closed contacts provide status 
bits. The interlock chain outputs are connected to Interlock Master Modules located in D5C. Status bits are read into ACNET through a multiplexer in R4A, and can be displayed on parameter page S40. Any alarm slot may be bypassed by inserting a "dummy" printed circuit card in place of a module.

Each interlock master module sums 5 inputs and provides 3 reed relay contact closure outputs. A circuit schematic is shown in Figure 4. Input 1 requires +5 volts, and directly energizes an interlock chain relay. Input 2 and 3 require TTL logic levels, and inputs 4 and 5 require and external contact closure. Internal switches select which inputs are active

Interlock master interconnections are shown in Figure 5. The lens uses two masters, one for water conductivity and the other for all interlocked conditions. The Conductivity Master controls the lens water purging system and also energizes one input of the General Master. The General Master provides the external interlock for the pulsed power supply.

If 1 ithium comes into contact with the cooling water, the conductivity master will trip. Output 2 of the Master shuts off the water circulating pump and initiates purging hardware, which isolates the lens from the water supply and allows inert gas to force remaining water from the lens into a reservoir located in the vault. Output 1 of the Master, which is connected to input 4 of the lens General Master, causes the General Master to trip and disable the pulsed power supply.

All other lens alarm conditions (except conductivity) enter input 1 and 2 of the Lens General Master. An alarm condition from these inputs will disable the pulsed power supply, but the water system will remain on.

Each interlock master has a manual Emergency Stop pushbutton (red) on its front panel. The pushbutton has alternating action, one push enabling the interlock master, the next push opening the interlock chain. all interlock masters are connected to an audible trip alarm module located in $\mathrm{R} 5 \mathrm{E}-6$. 
Table 1

Lithium lens signal conditioner (amplifier) and alarm/limit assignments

\section{Quantity}

Lens TC-A

Lens $\mathrm{TC}-\mathrm{B}$

Transformer TC-A

Transformer TC-B

$\mathrm{H}_{2} \mathrm{O}$ primary supply TC

Primary return TC

lens supply TC

lens return TC

ht. exch. out TC

primary return flow

lens supply flow

lens return flow

primary supply pressure

primary return pressure

lens supply pressure

lens return pressure

lens supply conductivity

lens return conductivity

circ. pump inlet pressure

Lens bias current

Power Supply peak cap. voltage

\begin{tabular}{|c|c|c|c|}
\hline $\begin{array}{c}\text { Signal } \\
\text { Conditioner } \\
\text { Slot }\end{array}$ & $\begin{array}{l}\text { Alarm } \\
\text { Card } \\
\text { Slot }\end{array}$ & $\begin{array}{l}\text { High } \\
\text { Limit }\end{array}$ & $\begin{array}{l}\text { Low } \\
\text { Limit }\end{array}$ \\
\hline $\begin{array}{r}\mathrm{R} 5 \mathrm{C}-0 \\
-1 \\
-2 \\
-3 \\
-4 \\
-5 \\
-6 \\
-7 \\
-9\end{array}$ & $\begin{array}{r}R 6 B-1 \\
-2 \\
-3 \\
-4\end{array}$ & $\begin{array}{l}70^{\circ} \mathrm{C} \\
70^{\circ} \mathrm{C} \\
80^{\circ} \mathrm{C} \\
80^{\circ} \mathrm{C}\end{array}$ & $\begin{array}{l}10^{\circ} \mathrm{C} \\
10^{\circ} \mathrm{C} \\
15^{\circ} \mathrm{C} \\
15^{\circ} \mathrm{C}\end{array}$ \\
\hline $\begin{array}{r}\text { R5F }-15 \\
\text { R5C-10 } \\
-11 \\
\text { R5F-10 } \\
-12\end{array}$ & $\begin{array}{r}R 6 C-3 \\
-4\end{array}$ & $\begin{array}{ll}3.4 & \mathrm{GPM} \\
3.4 & \mathrm{GPM}\end{array}$ & $\begin{array}{ll}1.3 & \mathrm{GPM} \\
1.3 & \mathrm{GPM}\end{array}$ \\
\hline $\begin{array}{r}\mathrm{R} 5 \mathrm{C}-12 \\
-13 \\
\mathrm{R} 5 \mathrm{~F}-13\end{array}$ & $\begin{array}{l}-5 \\
-6\end{array}$ & $\begin{array}{l}200 \mathrm{psi} \\
100 \mathrm{psi}\end{array}$ & $\begin{array}{rl}60 & \mathrm{psi} \\
5 & \mathrm{psi}\end{array}$ \\
\hline $\begin{array}{r}R 5 C-14 \\
-15 \\
R 5 E-14\end{array}$ & $\begin{array}{r}-10 \\
-8 \\
-1\end{array}$ & $\begin{array}{l}1 \mu \mathrm{mho} / \mathrm{cm} \\
20 \mathrm{psi}\end{array}$ & $1.5 \mathrm{psi}$ \\
\hline
\end{tabular}




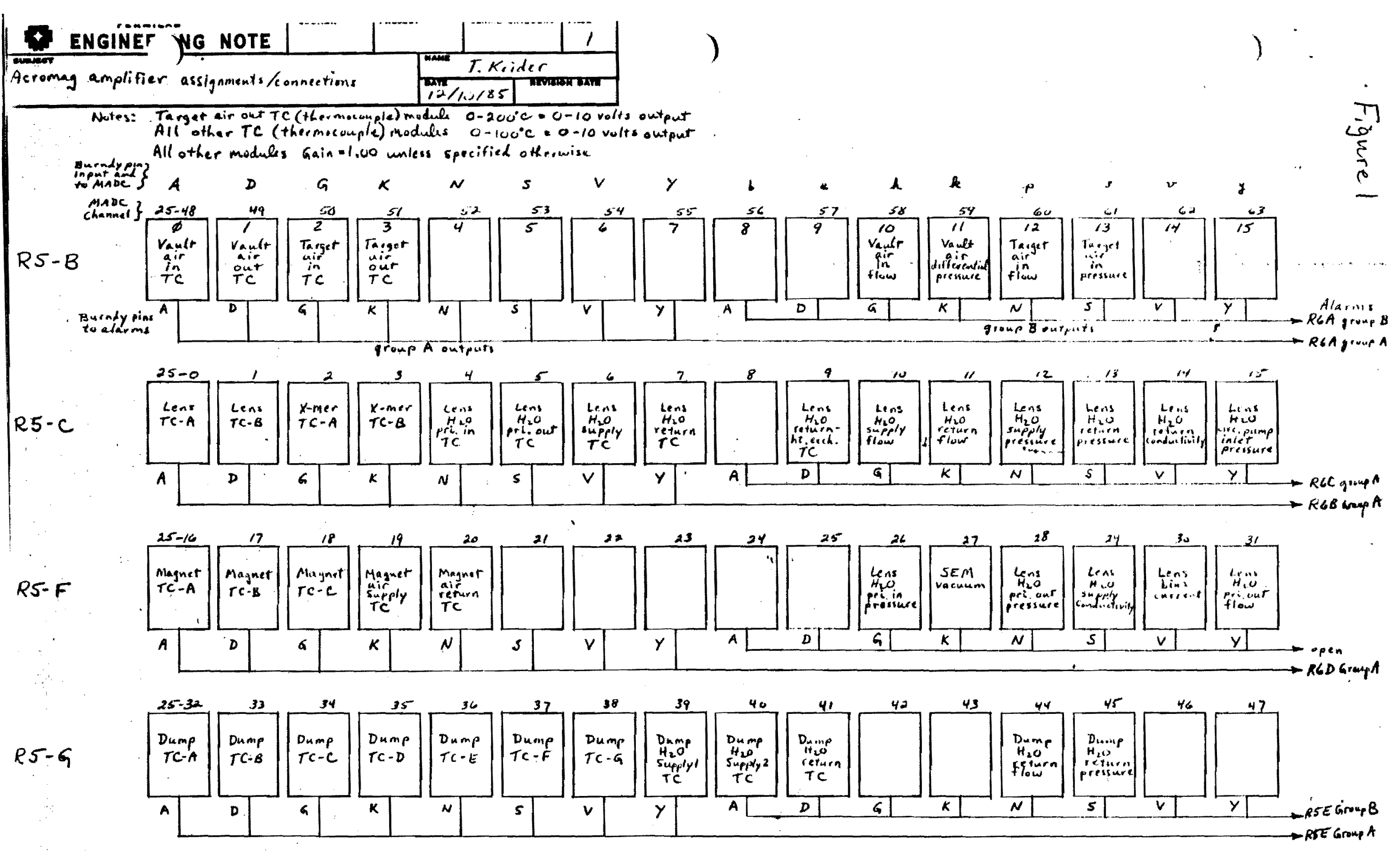




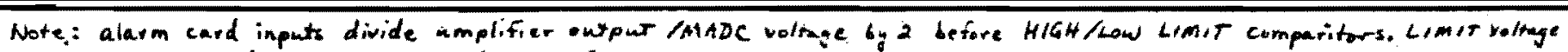
setring zuated on this page are at the comparitur impur.

- Input Burndy pinc $B, E, H, L, P, T, W, Z, e, f=$ grounded side of twistel pairs

\section{$25 B$}

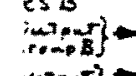

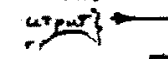

Q6 A

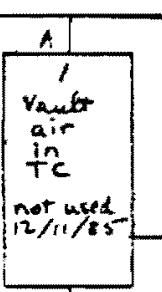

G $\quad$ Groue $R$ inemst

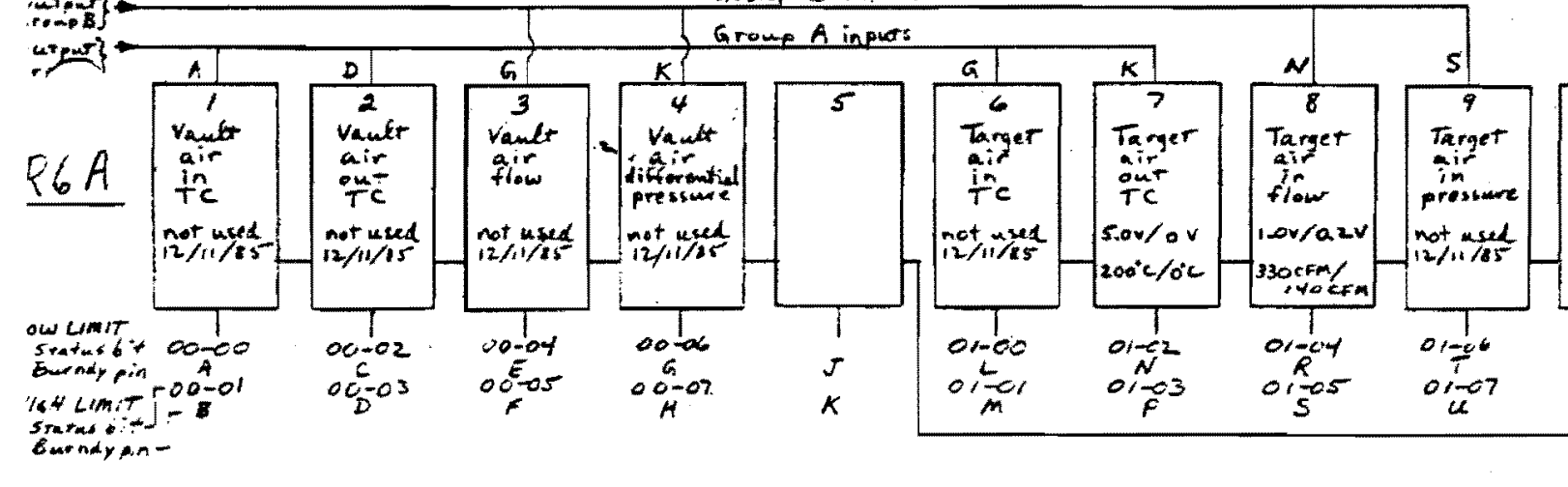

jucte C
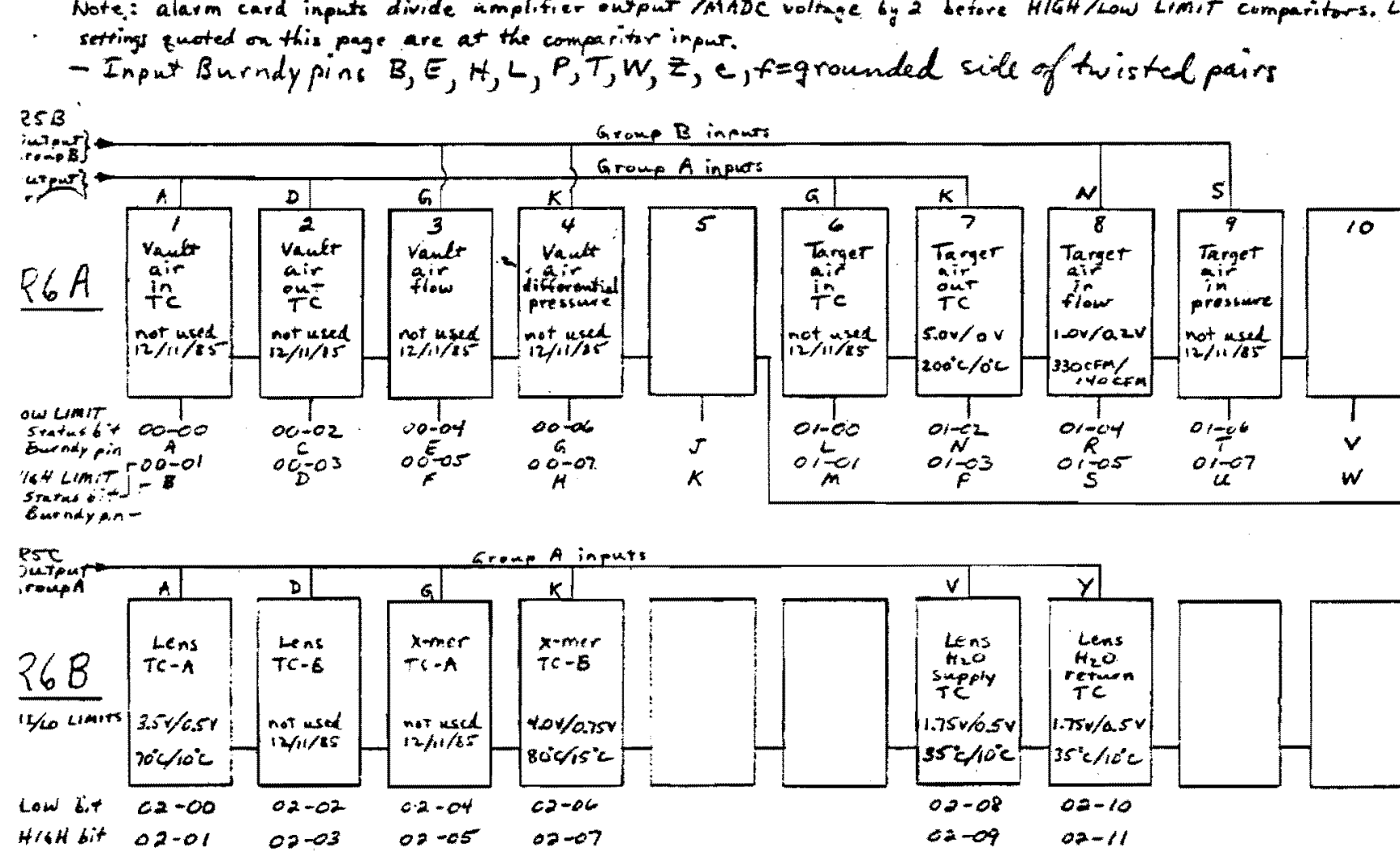

mita roup $A$ inpur

\section{$R 5 C$}

Form?

Finter

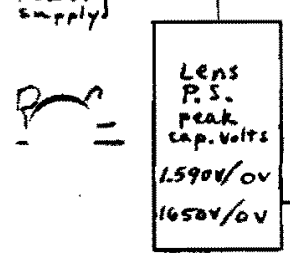

Low bit

$03-\infty$

Hith bit 03-09

Group 1 input:
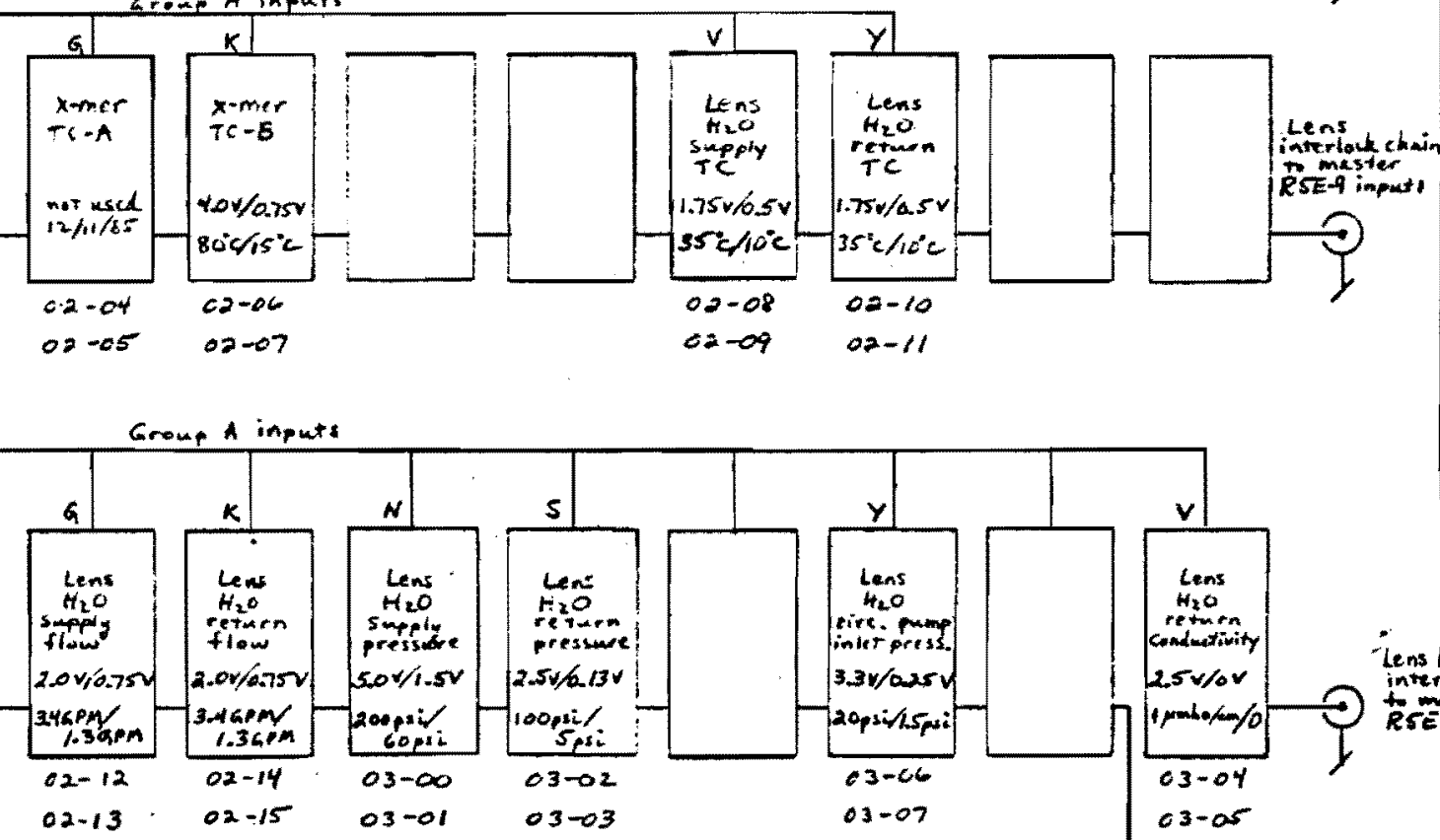

Teryer air

to maiter

RSE 8 input

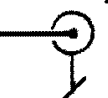

$\checkmark$ Vautrair

$W$ interiack chat

L. $5 \frac{1}{5}$

$$
03-\infty
$$

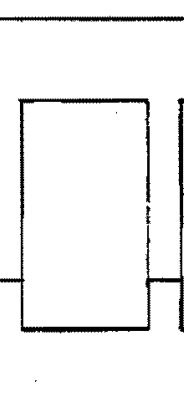

$02-13.02-15$

$03-01$

$03-03$
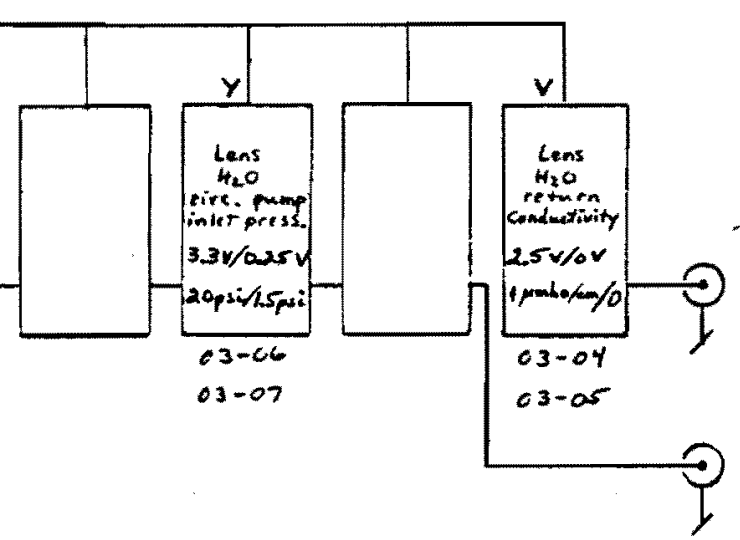

Lens $\mathrm{K}_{2} \mathrm{O}$ Conductivity interlace chein RSE-10 inmut

Ref Group A inputs
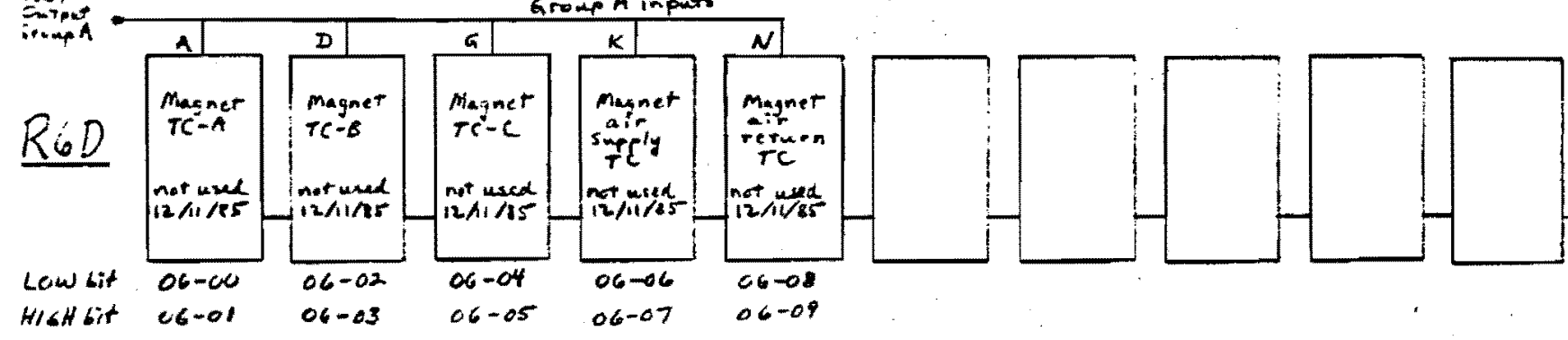

Lens RrE-9 input 2

R $5 G$

?imin- B

Grome B inputs

heremp Group A inpute

$R 6$

Low bit

Hink bit

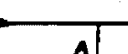

D 6

ats




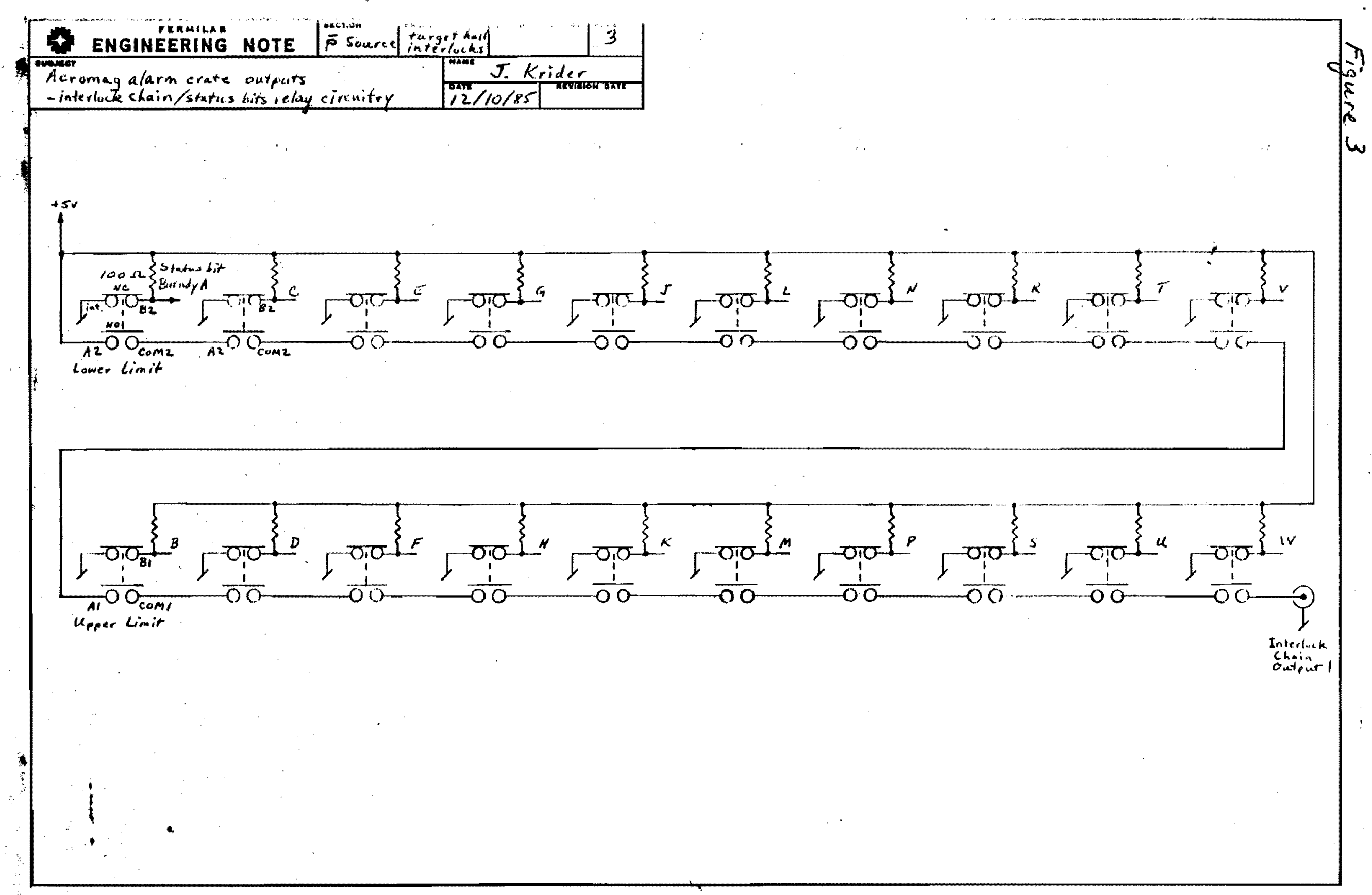


Figure 4

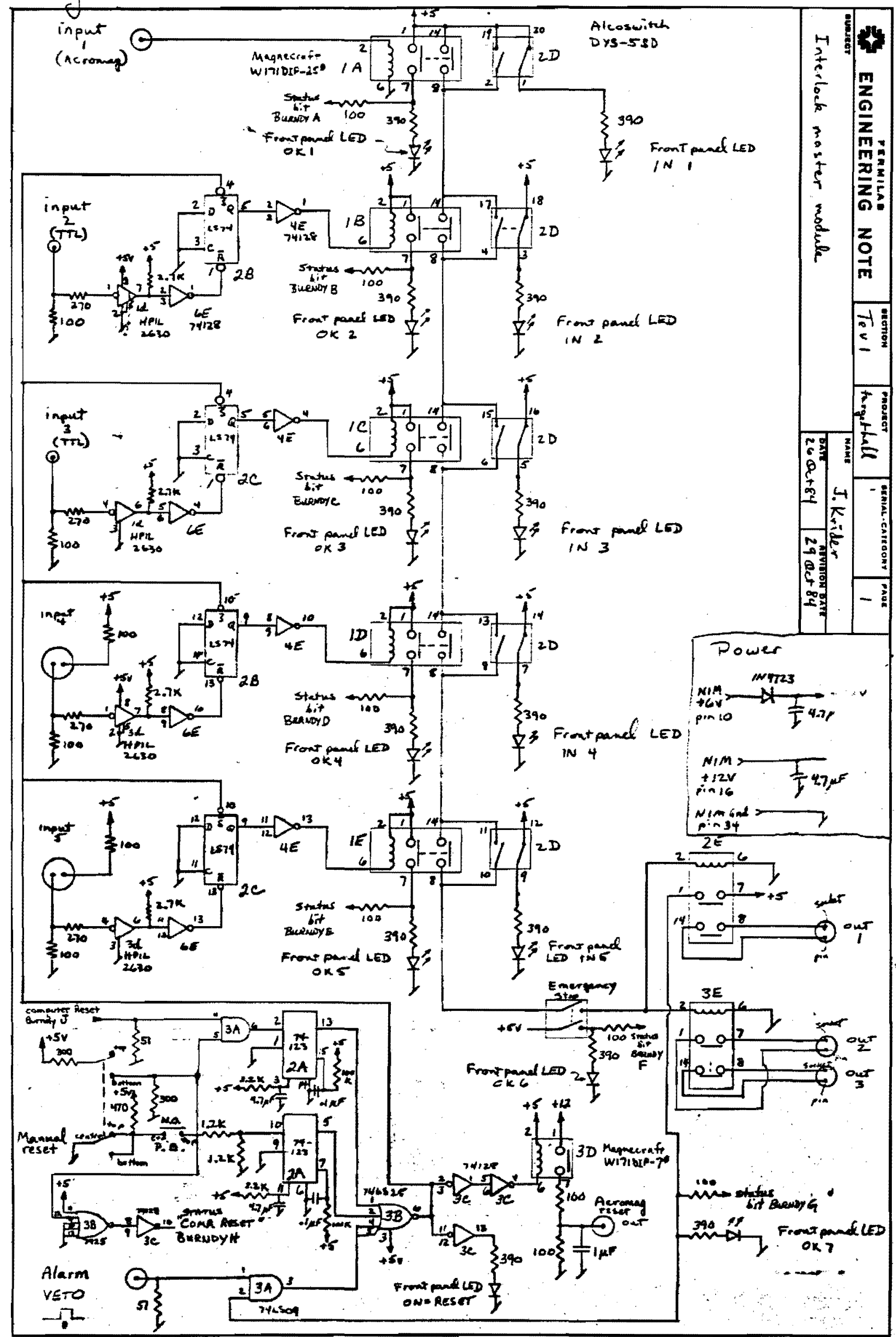


